Effects of motifs in music therapy on the attention of children with externalising

behaviour problems

King-chi Yau \& Jörg Fachner

Cambridge Institute for Music Therapy Research, ARU

Corresponding author:

King-chi Yau

Cambridge Institute for Music Therapy Research, ARU, Young Street, Cambridge, CB1 2LZ, UK

Email: king.yau@student.anglia.ac.uk 


\section{Effects of motifs in music therapy on the attention of children with externalising}

\section{behaviour problems}

\section{Abstract}

Recent studies highlight the role of attention (i.e. executive attention and joint attention) in the negative association between children's externalising behaviour problems (EBP) and self-regulation. In music therapy improvisation, 'Motifs' represent a repeated and meaningful use of freely improvised or structured music. They have been reported to be effective in drawing attention towards joint musical engagement. This study aimed to examine the effects of clinically derived Motifs on the attention of a child with EBPs. Video microanalysis of four therapy sessions was employed. Interaction segments with/without Motifs were then selected for analysis: (1) Executive attention measurement: a two-way ANOVA was conducted to examine the effects of Motifs (Factor I) across sessions (Factor II) on the duration of interaction segments. (2) Joint attention measurement: another two-way ANOVA investigated the effects of these two factors on the duration of joint attentive responses in each segment. Results showed that (1) the segments with Motifs tended to decrease in duration throughout the sessions, while (2) these 
segments showed a significant increase in proportions of joint attentional responses. These findings suggest a positive effect of Motifs on enhancing efficiency of joint attention execution over time, indicating the child's recognition of the Motifs through learning.

\section{Keywords}

Attention, behaviour problems, music therapy, motifs, microanalysis 
Mental health problems of children can be classified into: (a) internalising problems (i.e. withdrawn behaviours or physiological complaints) and (b) externalising problems (i.e. acting-out behaviours; Achenbach, 1991; Campbell, 1995). 'Externalising Behaviour Problems' (EBPs) is a term used to describe the clinical and subclinical exhibition of these acting-out, disruptive behaviours (Graziano et al., 2015, p. 1337; Hautmann, Hanisch, Mayer, Plück, \& Döpfner, 2008, p. 363). In mainstream primary schools, children with EBPs suffer from a wide range of limitations in the cognitive and socio-emotional domains (Graziano et al., 2015). Specifically, their lack of attention can be detrimental to classroom learning. Music therapy has been used as a therapeutic tool with this population (Wigram, 2002). In particular, musical motifs in therapeutic improvisation are widely adopted by music therapy practitioners (Agrotou, 1988; Aigen, 1998; Carroll \& Lefebvre, 2013; Holck, 2004; Lee \& Houde, 2011; Pavlicevic, 1997; Wigram, 2004). This study uses microanalysis to analyse music therapy sessions with a child with EBPs, and identify the presence and/or role of musical motifs within the 
sessions. To our knowledge the current investigation is the first of its kind to investigate the effects of musical motifs in music therapy on the attention of children with EBPs.

Mental health of children with EBPs

The most common EBPs clinical diagnoses have been reported as conduct disorder (CD), oppositional defiant disorder (ODD), attention deficit/hyperactivity disorder (ADHD), or comorbidity of these three diagnoses (Dick, Viken, Kaprio, Pulkkinen, \& Rose, 2005). Furthermore, early childhood diagnoses of these clinical conditions are linked to a significant higher prediction of serious mental disorders later in the pre-adolescent, adolescent and adult's stage (Bongers, Koot, Van Der Ende, \& Verhulst, 2004; Mesman, Bongers, \& Koot, 2001). 
Attention in individuals with normal development

Attention is a widely studied area in human psychology (Broadbent, 1958; Treisman, 1964, 1993). One's attention can generally be understood as the abilities to select and focus, to sustain, to switch, and to divide the attention by rapidly switching the focus of orienting (Thaut \& Gardiner, 2014). Another possible categorising framework is based on the presence/absence of involvement of another human being, leading to the differentiation between executive attention and joint attention.

Executive attention refers to the ability to shift the attention to and sustain on a specific task, as well as control the impulses to perform out-of-task behaviours (Anderson \& Reidy, 2012; Rothbart, Sheese, Rueda, \& Posner, 2011). This definition is similar to that of Thaut and Gardiner's (2014) description (i.e. to select, sustain, and shift), but with the addition of regulation of impulses as an important component. Some researchers proposed attentional persistence (i.e. the time to focus on an assigned task) as a measurement of executive attention (Zhou et al., 2007). 
Joint attention refers to the ability of people directing their combined or 'joint' attention to a common object, and being aware of each other during the process (Reitman, 2005). Kim, Wigram, and Gold (2008) described joint attention in the context of music therapy as 'an interactive state of joint engagement that involves the child, the therapist, and objects, or events in either musical form, or in play' (p. 1759). In order to demonstrate the presence of joint attentive state in behavioural terms, psychologists have identified that when infants and children understand their partner's social cues in a joint attentive manner, they may show the observable behaviours of following eye gaze, initiating vocalisations, or altering their way of playing with an object (Reitman, 2005; Vaughan et al., 2012).

Attention of children with EBPs

Self-regulation refers to the voluntary processes to change or maintain the level of arousal of emotional and behavioural responses (Cameron Ponitz et al., 2008; Rothbart et al., 2011; Wilson, Petaja, Stevens, Mitchell, \& Peterson, 2011). One might speculate 
that the ability to self-regulate for children with EBPs is low. Research supports this hypothesis and finds that low self-regulation in children significantly predicts high emergence of EBPs, which means that a less self-regulated child shows much more behaviour problems in their social contexts (Eisenberg et al., 2000). Now, the question is, how can we improve a child's self-regulatory ability? It leads to the following discussion of a proposed intervening factor underlying the relationship between one's ability to self-regulate and perform pro-social behaviours.

Both executive attention and joint attention are believed to be essential components in (a) diminishing behavioural problems and (b) facilitating the self-regulatory process. Zhou et al. (2007) and Wilson et al. (2011) both found a significant negative correlation between a child's executive attentional ability and behaviour problems exhibited. Also, Morales, Mundy, Crowson, Neal, and Delgado (2005) posited that children's (executive) attentional skills contribute to their self-regulatory abilities. Furthermore, Sheinkopf, Mundy, Claussen, and Willoughby (2004) found that children's joint attention (e.g. following eye gaze) was negatively associated with disruptive behaviours including 
fighting, aggression, and so on. Several research findings (with two longitudinal studies) also suggested that joint attention in children was significantly related to their self-regulatory abilities exhibited, for example, delay of gratification, self-soothing, and so on (Morales et al., 2005; Raver, 1996; Vaughan et al., 2012).

To summarise the above discussion regarding EBPs, self-regulation, and attention, Figure 1 outlines their relationships based on the above research findings. EBPs seem to be effectively prevented from emerging by the child's high self-regulatory abilities which act as a protective factor. This protective component is postulated to be possibly governed by two intervening factors (i.e. the variables which might account for the negative association between EBPs and self-regulation): (a) their skills to deploy executive attention and (b) joint attention. Both of these may serve as the focussed areas of psychotherapeutic interventions, ultimately aiming to assist these children to develop more pro-social and adaptive behaviours.

(INSERT FIGURE 1 HERE) 
Music therapy in general

In a very broad sense, music therapy is seen as an evidence-based practice using music to achieve individualised goals, including but not limited to cognitive, communicative, emotional, sensorimotor, and psychosocial domains (Yinger, 2018). Formats of delivery can be provided as individual, group, or family sessions (Oldfield \& Flower, 2008; Reitman, 2005). Music therapy work includes but is not limited to, the following four areas: (1) children's facilities such as preschools; (2) mental health settings such as forensic centres; (3) medical settings such as NICU and palliative care; and (4) geriatric settings such as nursing homes. (Bunt, 1994; Yinger, 2018). Among these clients, children are of concern to the present study. Some music therapists have been working extensively with 'undiagnosed children with behaviour, communication, social or attentional problem' (Wigram, 2002, p. 176). Children with EBPs, who have serious behavioural, social, and attentional problems, seem to be part of the population that may benefit from music therapy interventions. Results from a RCT conducted by Kim et al. (2008) showed that music therapy is helpful in improving the attention of children with 
autism, who have serious communicative problems similar to that of clients with EBPs. Another study showed evidence of a positive effect of music therapy on joint attention of children with autism spectrum disorder (Reitman, 2005).

Music therapy musical technique - the Motifs

Key music therapy interventions include improvisation, singing, vocalising, and listening to recorded and live music (Geretsegger, Elefant, Mössler, \& Gold, 2014). The current investigation focusses on the improvisational model which has been found to be one of the effective techniques (Jacobsen \& McKinney, 2015; Kim et al., 2008). In music therapy improvisations, 'co-activity episodes' (Agrotou, 1988, p. 18), 'point of reference' (Pavlicevic, 1997, p. 75), 'working motifs' (Aigen, 1998, p. 234), 'leitmotif' (Wigram, 2004, p. 162), 'interaction theme' (Holck, 2004, p. 8), 'motivic cells' (Lee \& Houde, 2011, p. 393) and 'incorporating motifs' (Carroll \& Lefebvre, 2013, p. 17) have all been reported to be a focus of drawing attention towards joint musical engagement. These musical ideas usually 'arise out of joint improvisation between child and music 
therapist over a course of time and develop continuously' (Holck, 2004, p. 8). In the present study, these concepts are grouped together as the 'Motifs'. Wigram (2002) has categorised two major forms of musical techniques: (a) freely improvised music and (b) structured music. Based on the similarities and differences of various Motifs' definitions from the above researchers, the current study summarises the findings and defines Motifs as a repeated and meaningful use of freely improvised or structured music, which emerged in earlier or later sessions and will be used for the therapist-child interaction to return to, anchor, and start again.

In a clinical vignette of the current study, a therapist used a rhythmic phrase<smiles>CC(C)(C)C(C)(C)C1CCC1</smiles>
on the keyboard to match a child's vigorous drumming. In a later session, when the child played the vigorous drumming again, the therapist repeated the usage of the rhythmic phrase improvisational nature of the therapy. The child and the therapist smiled to each other at this point, showing their mutual understanding of a meaningful interaction. Besides the use of instrumental improvisations, Motifs can also be manifested as a repeated 
introduction of game rules (i.e. a set of instructions given by the therapist on how to play) for a 'well-organised interaction' to happen in a musical activity (Agrotou, 1993, p. 183).

In order to identify particular Motifs, the present study adopted a broader definition of this anchoring point in musical interactions. To be more precise, it did not restrict the application of exactly the same musical or thematic contents throughout sessions, as long as there was an identification of sequential moments of a particular application of musical or interactional patterns (e.g. initiation of clear game rules before playing, such as those found in song-writing, action songs) across various sessions.

\section{Theoretical framework}

In summary, music therapy can potentially be helpful in assisting children with EBPs who have low self-regulatory ability. Executive attention and joint attention seem to play significant roles in the negative association between self-regulation and EBPs (see 
Figure 2). Holck (2007) declared that in music therapy, a meaningful interaction is the situation when both parties attend to and continue the interplay. The use of Motifs seems to be effective in creating such a meaningful and attentive interaction.

(INSERT FIGURE 2 HERE)

(INSERT FIGURE 3 HERE)

\section{Hypotheses and framework of the study}

In the present study, the above theoretical conceptualisations of (a) the behavioural and self-regulatory problems of children with EBPs (see Figure 2) and (b) the use of Motifs in arousing attention (see Figure 3 ) led to the formulations of the following two research questions:

1. Can Motifs in music therapy improve executive attention of children with EBP?

2. Can Motifs in music therapy improve joint attention of children with EBP? 
In addressing these two research questions, the method of video microanalysis was adopted. Figure 4 outlines the overall framework of the project's design. First, the level of change in the child's executive attention (addressing question 1) was found through measuring the mean duration of the child-therapist interaction segments (i.e. a series of therapist-child interactions). A segment consisted of (a) the therapist's attention-arousing input with/without Motifs and (b) the child's behavioural responses. Zhou et al.'s (2007) study has also employed this kind of time measurement of task persistence to indicate one's executive attention. Second, the level of change in joint attentional responses (addressing question 2) was addressed through measuring the mean time of the child having joint attentive responses (i.e. eye-gaze following, attentive playing, or responsive vocalisation) in the interaction sequences/segments.

(INSERT FIGURE 4 HERE) 


\section{Methods}

\section{Participant}

The present study was an observational analysis of music therapy sessions with a 7-year-old male child referred to the Jerome Booth Music Therapy Centre, Cambridge, for therapy. The child was referred due to his serious EBPs demonstrated at school. The therapy goal was to decrease the behaviour problems, with an underlying objective to improve the child's attention based on the theoretical understanding (see Figure 2). The clinical sessions were conducted and recorded at the child's primary school. The therapy sessions and data collection started in October 2015. Data were collected for 5 months until February 2016.

Materials and apparatus

A HDD Panasonic Camera set on a tripod was used to record the session. The whole 30-minute session was recorded. 
Design and procedure for measuring attention in Motifs segments

For the present study, Plahl's (2007) model of video microanalysis served as an overall framework of methodology with the following steps:

Step 1 Constructing the category system for Motifs/no-Motifs segments

Step 2 Defining and selecting the sample of sequences

Step 3 Choosing the technique of coding

Step 4 Assessing reliability

Step 5 Analysing different attention-related parameters on a micro level

Step 1: Constructing the category system for Motifs/no-Motifs segments. To minimise the problem of redundancy in naming particular interaction sequences, three symbols were used to denote a specific child-therapist interplay segment (see Table 1). For the 
first column, either $\mathrm{M}$ or $\mathrm{N}$ was chosen to indicate the presence or absence of Motifs (i.e.

M: Motifs, N: no-Motifs) respectively. The second column indicated the session in which the interplay was being analysed, and it could either be session 1, 3, 5 or 7 (which will be explained later regarding the selection of sessions). For the last column, the type of Motifs used in the segment was shown with the symbols A, B and C (see Figure 5 for more details). Since each Motifs segment had its comparing without-Motifs segment, the third column's code in a no-Motifs interaction referred to the Motifs' type in the Motifs interaction to be compared with. For example, a N5C code referred to the interaction segment in session 5, which contained no Motifs in the Child-Therapist engagement, but this specific period of interactions was analysed as a segment compared with the Motifs-C interplay in the same session.

(INSERT TABLE 1 HERE)

Plahl's (2007) KAMUTHE coding system for communication data (which was targeted at the child's joint attentional responses to the therapist's input) in the interplay recorded (a) the attentive gaze, (b) the responsive play or musical activity, and (c) the 
vocalisations of a child (see Table 2). The previous KAMUTHE coding system used by Plahl (2007) targeted very young children with developmental disorders. The present project, which was a study of an older child with EBPs, adapted the codes so as to provide an age-appropriate (e.g. removal of the gesturing category which is more relevant to younger and non-verbal children) and attention-related (e.g. changing the 'touching an instrument' item into 'playing an instrument responding to therapist's playing') analysis. The adapted codes remained mutually exclusive and exhaustive (Plahl, 2007, p. 44).

Furthermore, the current study differentiated the coding items of the child's behaviour into positive (+) and negative (-), corresponding to the presence and absence of joint attentional responses to the therapist's input respectively. Table 2 shows all of the items under the three main categories.

(INSERT TABLE 2 HERE) 
Step 2: Defining and selecting the sample of sequences. In the present study, the video materials within a session were selected by 'event sampling' (i.e. a systematic selection of a series of particular events for analysis; Holck, 2007, p. 45; Scholtz, Voigt, \& Wosh, 2007, p. 70), with the extraction of interaction segments with (or without, for the sake of control comparison) the presence of Motifs. All the sessions were video-recorded. However, since the second session was used as a 'probing' session to confirm the emerging Motifs, data collected were not analysed. In order to present a consistent sequence of what happened during the therapy, the analysed sessions included the first, third, fifth, and seventh (four sessions in total).

Regarding the selection of the ecologically and clinically valid Motifs from the therapy, the beginning session was firstly recorded and analysed. The Motifs which (a) appeared the most, (b) were the most effective in engaging the child, and (c) were 'simple and self-generated' (Holck, 2004, p. 5) were identified in this beginning session. Then, video recording of the second session was analysed to see if the selected Motifs continue to emerge. In the present study, contents of the three identified Motifs are the 
therapist's application of a short melodic phrase followed by a contrasting rhythmic phrase (Motifs A), the therapist's use of singing voice (Motifs B), and the therapist's directive musical activity (Motifs C; see Figure 5).

(INSERT FIGURE 5 HERE)

The no-Motifs segment (e.g. N1B) to be compared with a particular with-Motifs segment (e.g. M1B) was chosen from two criteria: First, it was selected from the segment right before or after the period of Motifs-containing sequences identified (Criterion I). The reason was to ensure that the Motifs (e.g. M1B) and the comparing no-Motifs (e.g. N1B) segments were close to each other and their difference of the child's attention span was not due to the phase of a therapy session but the presence (or absence) of the Motifs. Secondly, the no-Motifs segment should not contain Motifs A, $\mathrm{B}$, or C (Criterion II).

Based on the above standardised procedures, within the four analysed sessions, the interaction segments, with or without Motifs, could basically be identified. However, a standardised measurement of the total time frame for these segments had to be agreed 
on among sessions. The total time frame for each of the chosen child-therapist interaction (i.e. segments M1A, N1A, M1B, N1B, M1C, N1C, M3A, N3A.., M7C, N7C) started at the moment when the therapist initiated a joint-attentive input, and ended when both the child and the therapist stopped the interaction.

Step 3: Choosing the technique of coding. Similar to Plahl (2007), the present study adopted the technique of 'continuous event coding' (p. 46). After marking the selected segments from the beginning until the end based on a standardised event sampling, the total time of that particular segment and within which the child is having a joint attentive state could be calculated (i.e. the sum of duration of GAZ+, PMA+ and $\mathrm{VOC}+)$.

Step 4: Assessing reliability. A test-retest reliability analysis of the KAMUTHE coding system was performed using the intraclass correlation model. For the present study, the 
test-retest reliabilities for items GAZ, PMA, and VOC were found to be $.95, .96$ and .83 respectively. However, for the inter-rater reliability, owing to the small scale of the project and a lack of funding, the current study could not afford to hire another investigator to code the sessions and test the inter-rater reliability of the measurement.

Step 5: Analysing different attention-related parameters on a micro level. Following steps 1 to 3, quantitative information about the child's attentional responses (i.e. for executive attention: duration of interaction segments; for joint attention: GAZ+, PMA+, VOC + in the segments) in the music therapy sessions could be obtained. Since different interplay segments (i.e. from M1A to N7C) have different lengths of time (ranging from $12 \mathrm{~s}$ to $156 \mathrm{~s}$; see Appendix 1), the average proportion of positive joint attentional responses in each segment was calculated by the following equation (and $\underline{12 \mathrm{~s}}$ was chosen as the common time frame for all the segments for convenience), all of the data of joint attentional responses in all segments were translated to a comparable length of time (see below and Appendix 2): 


$\left[\frac{(\text { Length of joint attentional responses) }(s)}{\text { (Length of a segment) }(s)}\right] \times 12 s$

Two-way ANOVAs were calculated to ensure that any mean differences found in the dependent variables (i.e. executive attention, joint attention) were not due to chance but the presence or absence of Motifs (Factor I) across sessions (Factor II) as independent variables. 


\section{Results}

Duration of interaction segments

\section{(INSERT FIGURE 6 HERE)}

A two-way ANOVA was conducted to examine the effects of Motifs (Factor I) across sessions (Factor II) on the mean duration of interaction segments (see Figure 6). There was a significant difference in the mean duration of segments with Motifs (M=62.92s, $\mathrm{SD}=44.98 \mathrm{~s})$ and without Motifs $(\mathrm{M}=22.67 \mathrm{~s}, \mathrm{SD}=11.28 \mathrm{~s}), F(1,16)=8.85, p<0.01 * *$. However, there was no significant main effect of sessions on the duration of segments, $F(3,16)=0.83, p=0.50$, and no significant interaction between effects of Motifs and sessions on the duration of segments, $F(3,16)=1.02, p=0.41$.

These results suggest that Motifs did have an effect on eliciting higher executive attention than interventions without Motifs. However, there was no statistical evidence showing that throughout sessions, the duration of interaction segments demonstrated significant changes in both cases. It is worth noting that in the with-Motifs situation, the 
duration of segments seemed to show a decreasing trend, which will be interpreted further in the "Discussion" section.

Duration of joint attention in interaction segments

(INSERT FIGURE 7 HERE)

A two-way ANOVA was conducted to examine the effects of Motifs (Factor I) across sessions (Factor II) on the mean duration of joint attention in each segment (see Figure 7). There were statistically significant differences in the:

1. effect of Motifs interventions (M=6.85s, $\mathrm{SD}=2.92 \mathrm{~s})$ and no-Motifs interventions $(\mathrm{M}=1.23 \mathrm{~s}, \mathrm{SD}=1.29 \mathrm{~s})$ on the mean duration of joint attention, $F$ $(1,16)=146.10, p<0.01^{* *} ;$ 
2. effect of sessions (the seventh session: $M=5.18 \mathrm{~s}, \mathrm{SD}=5.29 \mathrm{~s}$ versus first session: $\mathrm{M}=1.83 \mathrm{~s}, \mathrm{SD}=2.32 \mathrm{~s})$ on the mean duration of joint attention, $F(3,16)$ $=10.89, p<0.01^{* *} ;$ and

3. interaction effect between Motifs and sessions on the mean duration of joint attention, $F(3,16)=12.60, p<0.01^{* *}$. For the no-Motifs situation, when comparing the first and seventh sessions, there was no significant difference found in the duration of joint attention $(p=1.00)$. However, for the with-Motifs situation, increase in duration of joint attention from the first session to the seventh session was statistically significant $(p<0.01 * *)$.

These results suggest that Motifs had a significant effect on eliciting higher joint attention in an interaction segment than interventions without Motifs. This statistical difference was also found across sessions, suggesting that Motifs were statistically effective in both eliciting higher joint attention and increasing the joint attentive responses over time. 


\section{Discussion and conclusion}

An improvement in the efficiency of the child's execution of joint attention

To reiterate, the whole investigation aimed to address two main research questions:

1. Can Motifs in music therapy improve executive attention of children with EBP?

2. Can Motifs in music therapy improve joint attention of children with EBP?

Collection of quantitative data in a microanalysis addressed both Questions 1 and 2

(see Figure 4). At first glance, although findings on the duration of interaction segments

(i.e. the proposed measurement of executive attention) suggested that compared with no-Motifs interventions, the use of Motifs elicits higher executive attention, the decreasing trend of the duration of the with-Motifs segment over time seemed to imply a decreasing sustained attention to the musical tasks across sessions (see Figure 6), which appeared to be in contrast to the prediction of this study. However, when the 
quantitative data of the duration of joint attention in the child-therapist segments was also taken into account (see Figure 7), in these shorter and shorter interaction segments across sessions, the therapist's Motifs interventions (compared with no-Motifs input) actually elicited increasing proportion of the child's joint attentive responses. This finding echoes the assertion made by Vaughan et al. (2012) and their research study:

...it may be that young infants who are less regulated or inhibited are more likely to show concurrent high rates of shifting attention; however, over development, this high rate is refined to result in fewer incorrect/extraneous shifts of attention and more frequent relevant/correct shifts of attention... In this perspective, both infants that are high in shifting attention due to less inhibition and infants who are high in shifting attention due to better initial regulation end up at a common end point: one in which more efficient shifting of attention should predict better self-regulation at a later point in development. (p. 305) 
The current result of the child having a higher efficiency in shifting attention (i.e. the child to locate his attention both quickly (from an unrelated task) and correctly (to both the musical interaction and the therapist as a social partner)) can be explained by the concept of 'chunking'. This refers to the process of 'detecting and encoding regularities between items in working memory, thus aiding understanding... accelerated(ly)' (Bor \& Seth, 2012, p. 2). These regularities appear to be cultivated by the Motifs' repetitive nature, which allows the establishment of the Motifs-associated meaningful and rewarding social information (e.g. the 'happy' moment) in the child's memory (Gardiner \& Thaut, 2014). This continuing and repeating process of executing joint attention to the Motifs and therapist in turn reduces 'the cognitive resources ... (one) must allocate to the execution ... of ... attention' (Vaughan et al., 2012, p. 309).

The above argument (of explaining the child's improved efficiency of joint attention execution in terms of the theory of chunking) can be further supported by Piaget's concepts of schemata, accommodation, and assimilation. To illustrate, the child could be said to originally possess a social-related schema (i.e. fundamental mental 
organisation or structure; Piaget, 1952), which might be conjectured to be threatening and warranting avoidance from intimacy (and hence the non-attentive behaviours) for a child with EBPs. The Motifs-induced (social) stimuli (e.g. the musical phrase, therapist's engaging facial expression and vocalisations), which are so different from the child's existing knowledge/schema, introduce the process of accommodation to change his current mental understanding and expectation (Piaget, 1952). Through this repetitive process of continuous engagement with the child through Motifs, his original social schema is now updated. It can quickly assimilate (i.e. placing the received stimuli to an existing schema; Piaget, 1952) the Motifs stimuli and activate the assimilated knowledge of a non-threatening, engaging, and joint attentive interaction in an efficient manner.

Therefore, instead of stating the level of change in executive attention and joint attention separately, findings of the current investigation suggest the conclusion of an improvement in the efficiency of executing joint attention, attributed to the repetitive nature of Motifs and the corresponding chunking, accommodation, and assimilation of 
the adaptive social information. Chunking and Piaget's cognitive theories provide explanations on how repetitively engaging with Motifs can improve the joint attentional efficiency.

Limitations of the study and suggestions for future investigation

Lack of a representative number of population. The study sample of the current study only consists of a single case, which limits the ability to generalise the findings to explore the systematic effects of Motifs on the EBPs population. While this study presents a single case analysis, it provides a starting point to research the important clinical use of Motifs. Future studies are needed with a larger population of children with EBPs to allow for certain types of Motifs to be identified.

Lack of inter-rater reliability. Although the author's adoption of the microanalysis tool showed a high intra-rater reliability, inter-rater reliability was missing. This reliability 
measurement is important to ensure that the investigator is holding an objective view in coding the clinical sessions. Future studies should strive to include at least two coders to carry out the microanalytic coding.

\section{Conclusion}

Results from this study show a positive effect of Motifs on enhancing efficiency of joint attention execution of a child with EBPs. Future studies adopting the same microanalytic methodology on music therapy clinical sessions with the EBPs population are encouraged. This development will certainly contribute to the further exploration of how music therapy can be helpful to the well-being of our future generation. 


\section{References}

Achenbach, T.M. (1991). Manual for the child behavior checklist 4-18. Burlington, VT:

University of Vermont Department of Psychiatry.

Agrotou, A. (1993). Spontaneous ritualised play in music therapy. In M. Heal \& T.

Wigram (Eds.), Music therapy in health and education (pp. 175-192). London, UK:

Jessica Kingsley Publishers.

Agrotou, A. (1988). A case study: Lara. British Journal of Music Therapy, 2(1), 17-23.

Aigen, K. (1998). Path of development in Nordoff-Robbins music therapy. Gilsum, NH:

Barcelona Publishers.

Anderson, P.J., \& Reidy, N. (2012). Assessing executive function in preschoolers.

Neuropsychology Review, 22(4), 345-360. 
Bongers, I.L., Koot, H.M., Van Der Ende, J., \& Verhulst, F.C. (2004). Developmental trajectories of externalizing behaviors in childhood and adolescence. Child Development, 75(5), 1523-1537.

Bor, D., \& Seth, A.K. (2012). Consciousness and the prefrontal parietal network: Insights from attention, working memory, and chunking. Frontiers in Psychology, 3(63), 1-14.

Broadbent, D. (1958). Perception and communication. London: Pergamon Press.

Bunt, L. (1994). Music therapy: An art beyond words. London: Routledge.

Cameron Ponitz, C.E., McClelland, M.M., Jewkes, A.M., Connor, C.M., Farris, C.L., \& Morrison, F.J. (2008). Touch your toes! Developing a direct measure of behavioral regulation in early childhood. Early childhood Research Quarterly, 23(2), 141-158.

Campbell, S.B. (1995). Behavior problems in preschool children: A review of recent research. Journal of Child Psychology and Psychiatry, 36(1), 113-149. 
Carroll, D., \& Lefebvre, C. (2013). Clinical improvisation techniques in music therapy: A guide for students, clinicians and educators. Springfield, IL: Charles C Thomas.

Dick, D., Viken, R., J., Kaprio, J., Pulkkinen, L., \& Rose, R. J. (2005). Understanding the covariation among childhood externalizing symptoms: Genetic and environmental influences on conduct disorder, attention deficit hyperactivity disorder, and oppositional defiant disorder symptoms. Journal of Abnormal Child Psychology, 33(2), 219-229.

Eisenberg, N., Guthrie, I.K., Fabes, R.A., Shepard, S., Losoya, S., Murphy, B.C., Jones, S., Paulin, R., \& Reiser, M. (2000). Prediction of elementary school children's externalizing problem behaviors from attentional and behavioral regulation and negative emotionality. Child Development, 71(5), 1367-1382.

Gardiner, J.C., \& Thaut, M.H. (2014). Musical mnemonic training (MMT). In M.H. Thaut \& V. Hoemberg (Eds.), Handbook of neurologic music therapy (pp. 294-310). Oxford: Oxford University Press. 
Graziano, P.A., Slavec, J., Ros, R., Garb, L., Hart, K., \& Garcia, A. (2015).

Self-regulation assessment among preschoolers with externalizing behavior problems. Psychological Assessment, 27(4), 1337-1348.

Geretsegger, M., Elefant, C., Mössler, K.A., \& Gold, C. (2014). Music therapy for people with autism spectrum disorder. Cochrane Database of Systematic Reviews, 6, CD004381.Hautmann, C., Hanisch, C., Mayer, I., Plück, J., \& Döpfner, M. (2008). Effectiveness of the prevention program for externalizing problem behaviour (PEP) in children with symptoms of attention-deficit/hyperactivity disorder and oppositional defiant disorder - generalization to the real world. Journal of Neural Transmission, 115(2), 363-370.

Holck, U. (2007). An ethnographic descriptive approach to video microanalysis. In T. Wosch \& T. Wigram (Eds.), Microanalysis in music therapy: Methods, techniques and applications for clinicians, researchers, educators and students (pp. 29-40). London, UK: Jessica Kingsley Publishers. 
Holck, U. (2004). Interaction themes in music therapy: Definition and delimitation. Nordic Journal of Music Therapy, 13(1), 3-19.

Jacobsen, S., \& McKinney, L. (2015). A music therapy tool for assessing parent-child interaction in cases of emotional neglect. Journal of Child and Family Studies, 24(7), 2164-2173.Kim, J., Wigram, T., \& Gold, C. (2008). The effects of improvisational music therapy on joint attention behaviors in autistic children: A randomized controlled study. Journal of Autism and Developmental Disorders, 38(9), 1758-1766.

Lee, C.H., \& Houde, M. (2011). Improvising in styles: A workbook for music therapists, educators, and musicians. Gilsum, NH: Barcelona Publishers.

Mesman, J., Bongers, I.L., \& Koot, H.M. (2001). Preschool developmental pathways to preadolescent internalizing and externalizing problems. Journal of Child Psychology and Psychiatry, 42(5), 679-689. 
Morales, M., Mundy, P., Crowson, M.M., Neal, A.R., \& Delgado, C.E.F. (2005).

Individual differences in infant attention skills, joint attention, and emotion regulation behaviour. International Journal of Behavioral Development, 29(3), 259-263.

Oldfield, A., \& Flower, C. (2008). Music therapy with children and their families. London, UK: Jessica Kingsley Publishers.

Pavlicevic, M. (1997). Music therapy in context: Music, meaning and relationship. London, UK: Jessica Kingsley Publishers.

Piaget, J. (1952). The origins of intelligence in children. New York, NY: International Universities Press.

Plahl, C. (2007). Microanalysis of preverbal communication in music therapy. In T. Wosch \& T. Wigram (Eds.), Microanalysis in music therapy: Methods, techniques and applications for clinicians, researchers, educators and students (pp. 41-53). London, UK: Jessica Kingsley Publishers. 
Raver, C.C. (1996). Relations between social contingency in mother-child interaction and 2-year-olds' social competence. Developmental Psychology, 32(5), 850-859.

Reitman, M.R. (2005). Effectiveness of music therapy interventions on joint attention in children diagnosed with autism: A pilot study (Doctoral dissertation). Retrieved from Proquest Dissertations and Theses (3195248).

Rothbart, M.K., Sheese, B.E., Rueda, M.R., \& Posner, M.I. (2011). Developing mechanisms of self- regulation in early life. Emotion Review, 3(2), 207-213.

Scholtz, J., Voigt, M., \& Wosch, T. (2007). Microanalysis of interaction in music therapy (MIMT) with children with developmental disorders. In T. Wosch \& T. Wigram (Eds.), Microanalysis in music therapy: Methods, techniques and applications for clinicians, researchers, educators and students (pp. 67-78). London, UK: Jessica Kingsley Publishers. Sheinkopf, S.J., Mundy, P., Claussen, A.H., \& Willoughby, J. (2004). Infant joint attention skill and preschool behavioral outcomes in at-risk children. Development and Psychopathology, 16(2), 273-291. 
Thaut, M.H., \& Gardiner, J.C. (2014). Musical attention control training. In M.H. Thaut \& V. Hoemberg (Eds.), Handbook of neurologic music therapy (pp. 257-269). Oxford: Oxford University Press.

Treisman, A.M. (1964). Selective attention in man. British Medical Bulletin, 20, 12-16.

Treisman, A.M. (1993). The perception of features and objects. In A. Baddeley \& L. Weiskrantz (Eds.), Attention: Selection, awareness, and control. Oxford: Clarendon Press.

Vaughan, V.H., Mundy, P., Block, J.J., Delgado, C.E.F., Parlade, M.V., Pomares, Y.B., \& Hobson, J.A. (2012). Infant responding to joint attention, executive processes, and self-regulation in preschool children. Infant Behavior and Development, 35(2), 303-311.

Wigram, T. (2004). Improvisation: Methods and techniques for music therapy clinicians, educators and students. London, UK; New York, NY: Jessica Kingsley Publishers. 
Wigram, T. (2002). A comprehensive guide to music therapy: Theory, clinical practice, research and training. London, UK; Philadelphia, PA: Jessica Kingsley Publishers.

Wilson, B.J., Petaja, H.S., Stevens, A.D., Mitchell, M.F., \& Peterson, K.M. (2011).

Children's responses to entry failure: Attention deployment patterns and self-regulation skills. The Journal of Genetic Psychology, 172(4), 376-400.

Yinger, O.S. (2018). Music therapy: Research and evidence-based practice. USA: Elsevier.

Zhou, Q., Hofer, C., Eisenberg, N., Reiser, M., Spinrad, T.L., \& Fabes, R.A. (2007). The developmental trajectories of attention focusing, attentional and behavioral persistence, and externalizing problems during school-age years. Developmental Psychology, 43(2), 369-385. 


\section{Appendices}

Appendix 1: Duration of joint attentional responses in each segment (before adjustment)

\begin{tabular}{|c|c|c|c|c|}
\hline \multirow{2}{*}{$\begin{array}{l}\text { Duration of } \\
\text { interaction } \\
\text { segments }\end{array}$} & \multicolumn{4}{|c|}{ Duration of joint attentional responses } \\
\hline & GAZ (+) & PMA (+) & VOC (+) & $\begin{array}{l}\text { Total value of } \\
\text { joint attention }\end{array}$ \\
\hline M1A: 116s & $\begin{array}{l}\text { GAZ-1: 4s } \\
\text { GAZ-2: } 6 s\end{array}$ & $\begin{array}{l}\text { PMA-1: } 6 \mathrm{~s} \\
\text { PMA-2: } 0\end{array}$ & $\begin{array}{l}\text { VOC-1: } 0 \\
\text { VOC-2: } 1 \mathrm{~s} \\
\text { VOC-3: } 1 \mathrm{~s}\end{array}$ & $18 \mathrm{~s}$ \\
\hline N1A: $12 \mathrm{~s}$ & $\begin{array}{l}\text { GAZ-1: } 0 \\
\text { GAZ-2: } 0\end{array}$ & $\begin{array}{l}\text { PMA-1: } 0 \\
\text { PMA-2: } 0\end{array}$ & $\begin{array}{l}\text { VOC-1: } 0 \\
\text { VOC-2: } 0 \\
\text { VOC-3: } 0\end{array}$ & 0 \\
\hline M1B: 20s & $\begin{array}{l}\text { GAZ-1: } 6 \mathrm{~s} \\
\text { GAZ-2: } 0\end{array}$ & $\begin{array}{l}\text { PMA-1: } 0 \\
\text { PMA-2: } 0\end{array}$ & $\begin{array}{l}\text { VOC-1: } 0 \\
\text { VOC-2: } 0 \\
\text { VOC-3: } 0\end{array}$ & $6 s$ \\
\hline N1B: $12 \mathrm{~s}$ & $\begin{array}{l}\text { GAZ-1: } 0 \\
\text { GAZ-2: } 0\end{array}$ & $\begin{array}{l}\text { PMA-1: } 0 \\
\text { PMA-2: } 0\end{array}$ & $\begin{array}{l}\text { VOC-1: } 0 \\
\text { VOC-2: } 0 \\
\text { VOC-3: } 0\end{array}$ & 0 \\
\hline M1C:156s & $\begin{array}{l}\text { GAZ-1: } 36 \mathrm{~s} \\
\text { GAZ-2: } 26 \mathrm{~s}\end{array}$ & $\begin{array}{l}\text { PMA-1: } 0 \\
\text { PMA-2: } 5 \mathrm{~s}\end{array}$ & $\begin{array}{l}\text { VOC-1: } 0 \\
\text { VOC-2: } 2 \mathrm{~s} \\
\text { VOC-3: } 3 \mathrm{~s}\end{array}$ & $72 s$ \\
\hline N1C: 26s & $\begin{array}{l}\text { GAZ-1: } 0 \\
\text { GAZ-2: } 0\end{array}$ & $\begin{array}{l}\text { PMA-1: } 0 \\
\text { PMA-2: } 0\end{array}$ & $\begin{array}{l}\text { VOC-1: } 0 \\
\text { VOC-2: } 0 \\
\text { VOC-3: } 0\end{array}$ & 0 \\
\hline M3A: $50 \mathrm{~s}$ & $\begin{array}{l}\text { GAZ-1: 4s } \\
\text { GAZ-2: } 0\end{array}$ & $\begin{array}{l}\text { PMA-1: } 19 \mathrm{~s} \\
\text { PMA-2: } 0\end{array}$ & $\begin{array}{l}\text { VOC-1: } 0 \\
\text { VOC-2: } 3 \mathrm{~s} \\
\text { VOC-3: } 2 \mathrm{~s}\end{array}$ & $28 \mathrm{~s}$ \\
\hline
\end{tabular}




\begin{tabular}{|c|c|c|c|c|}
\hline $\mathrm{N} 3 \mathrm{~A}: 21 \mathrm{~s}$ & $\begin{array}{l}\text { GAZ-1: 2s } \\
\text { GAZ-2: } 1 \mathrm{~s}\end{array}$ & $\begin{array}{l}\text { PMA-1: } 0 \\
\text { PMA-2: } 0\end{array}$ & $\begin{array}{l}\text { VOC-1: } 0 \\
\text { VOC-2: } 1 \mathrm{~s} \\
\text { VOC-3: } 2 \mathrm{~s}\end{array}$ & $6 s$ \\
\hline M3B: $38 \mathrm{~s}$ & $\begin{array}{l}\text { GAZ-1: } 3 \mathrm{~s} \\
\text { GAZ-2: } 0\end{array}$ & $\begin{array}{l}\text { PMA-1: } 12 \mathrm{~s} \\
\text { PMA-2: } 0\end{array}$ & $\begin{array}{l}\text { VOC-1: } 0 \\
\text { VOC-2: } 2 \mathrm{~s} \\
\text { VOC-3: } 0\end{array}$ & $17 \mathrm{~s}$ \\
\hline $\mathrm{N} 3 \mathrm{~B}: 20 \mathrm{~s}$ & $\begin{array}{l}\text { GAZ-1: 1s } \\
\text { GAZ-2: } 0\end{array}$ & $\begin{array}{l}\text { PMA-1: } 0 \\
\text { PMA-2: } 0\end{array}$ & $\begin{array}{l}\text { VOC-1: } 0 \\
\text { VOC-2: } 0 \\
\text { VOC-3: } 3 \mathrm{~s}\end{array}$ & $4 \mathrm{~s}$ \\
\hline M3C: $72 \mathrm{~s}$ & $\begin{array}{l}\text { GAZ-1: 10s } \\
\text { GAZ-2: } 5 \mathrm{~s}\end{array}$ & $\begin{array}{l}\text { PMA-1: } 0 \\
\text { PMA-2: } 0\end{array}$ & $\begin{array}{l}\text { VOC-1: } 0 \\
\text { VOC-2: } 2 \mathrm{~s} \\
\text { VOC-3: } 5 \mathrm{~s}\end{array}$ & $22 \mathrm{~s}$ \\
\hline N3C: 21s & $\begin{array}{l}\text { GAZ-1: 2s } \\
\text { GAZ-2: 1s }\end{array}$ & $\begin{array}{l}\text { PMA-1: } 0 \\
\text { PMA-2: } 0\end{array}$ & $\begin{array}{l}\text { VOC-1: } 0 \\
\text { VOC-2: } 1 \mathrm{~s} \\
\text { VOC-3: } 2 \mathrm{~s}\end{array}$ & $6 s$ \\
\hline M5A: 36s & $\begin{array}{l}\text { GAZ-1: } 1 \mathrm{~s} \\
\text { GAZ-2: } 2 \mathrm{~s}\end{array}$ & $\begin{array}{l}\text { PMA-1: 22s } \\
\text { PMA-2: } 0\end{array}$ & $\begin{array}{l}\text { VOC-1: } 0 \\
\text { VOC-2: } 0 \\
\text { VOC-3: } 0\end{array}$ & $25 \mathrm{~s}$ \\
\hline N5A: $28 \mathrm{~s}$ & $\begin{array}{l}\text { GAZ-1: 1s } \\
\text { GAZ-2: } 0\end{array}$ & $\begin{array}{l}\text { PMA-1: } 0 \\
\text { PMA-2: } 0\end{array}$ & $\begin{array}{l}\text { VOC-1: } 0 \\
\text { VOC-2: } 1 \mathrm{~s} \\
\text { VOC-3: } 2 \mathrm{~s}\end{array}$ & $4 s$ \\
\hline M5B: $112 \mathrm{~s}$ & $\begin{array}{l}\text { GAZ-1: } 5 \mathrm{~s} \\
\text { GAZ-2: } 8 \mathrm{~s}\end{array}$ & $\begin{array}{l}\text { PMA-1: } 61 \mathrm{~s} \\
\text { PMA-2: } 0\end{array}$ & $\begin{array}{l}\text { VOC-1: } 0 \\
\text { VOC-2: } 2 \mathrm{~s} \\
\text { VOC-3: } 0\end{array}$ & $76 s$ \\
\hline N5B: $28 \mathrm{~s}$ & $\begin{array}{l}\text { GAZ-1: 1s } \\
\text { GAZ-2: } 0\end{array}$ & $\begin{array}{l}\text { PMA-1: } 0 \\
\text { PMA-2: } 0\end{array}$ & $\begin{array}{l}\text { VOC-1: } 0 \\
\text { VOC-2: } 1 \mathrm{~s} \\
\text { VOC-3: } 2 \mathrm{~s}\end{array}$ & $4 \mathrm{~s}$ \\
\hline M5C: $31 \mathrm{~s}$ & $\begin{array}{l}\text { GAZ-1: 10s } \\
\text { GAZ-2: } 0\end{array}$ & $\begin{array}{l}\text { PMA-1: } 0 \\
\text { PMA-2: } 7 \mathrm{~s}\end{array}$ & $\begin{array}{l}\text { VOC-1: } 0 \\
\text { VOC-2: } 5 \mathrm{~s} \\
\text { VOC-3: } 2 \mathrm{~s}\end{array}$ & $24 \mathrm{~s}$ \\
\hline
\end{tabular}




\begin{tabular}{|c|c|c|c|c|}
\hline N5C: $54 \mathrm{~s}$ & $\begin{array}{l}\text { GAZ-1: } 0 \\
\text { GAZ-2: } 1 \mathrm{~s}\end{array}$ & $\begin{array}{l}\text { PMA-1: } 0 \\
\text { PMA-2: } 0\end{array}$ & $\begin{array}{l}\text { VOC-1: } 0 \\
\text { VOC-2: } 0 \\
\text { VOC-3: } 2 \mathrm{~s}\end{array}$ & $3 \mathrm{~s}$ \\
\hline M7A: $17 \mathrm{~s}$ & $\begin{array}{l}\text { GAZ-1: } 5 \mathrm{~s} \\
\text { GAZ-2: } 0\end{array}$ & $\begin{array}{l}\text { PMA-1: } 0 \\
\text { PMA-2: 4s }\end{array}$ & $\begin{array}{l}\text { VOC-1: } 0 \\
\text { VOC-2: } 2 \mathrm{~s} \\
\text { VOC-3: } 0\end{array}$ & $11 \mathrm{~s}$ \\
\hline N7A: $17 \mathrm{~s}$ & $\begin{array}{l}\text { GAZ-1: } 1 \mathrm{~s} \\
\text { GAZ-2: } 0\end{array}$ & $\begin{array}{l}\text { PMA-1: } 0 \\
\text { PMA-2: } 0\end{array}$ & $\begin{array}{l}\text { VOC-1: } 0 \\
\text { VOC-2: } 0 \\
\text { VOC-3: } 0\end{array}$ & $1 \mathrm{~s}$ \\
\hline M7B: 25s & $\begin{array}{l}\text { GAZ-1: } 3 \mathrm{~s} \\
\text { GAZ-2: } 15 \mathrm{~s}\end{array}$ & $\begin{array}{l}\text { PMA-1: } 0 \\
\text { PMA-2: } 0\end{array}$ & $\begin{array}{l}\text { VOC-1: } 0 \\
\text { VOC-2: } 3 \mathrm{~s} \\
\text { VOC-3: } 2 \mathrm{~s}\end{array}$ & $23 \mathrm{~s}$ \\
\hline N7B: $16 \mathrm{~s}$ & $\begin{array}{l}\text { GAZ-1: } 0 \\
\text { GAZ-2: } 0\end{array}$ & $\begin{array}{l}\text { PMA-1: } 0 \\
\text { PMA-2: } 0\end{array}$ & $\begin{array}{l}\text { VOC-1: } 0 \\
\text { VOC-2: } 0 \\
\text { VOC-3: } 0\end{array}$ & 0 \\
\hline M7C: $82 \mathrm{~s}$ & $\begin{array}{l}\text { GAZ-1: 39s } \\
\text { GAZ-2: } 23 \mathrm{~s}\end{array}$ & $\begin{array}{l}\text { PMA-1: } 0 \\
\text { PMA-2: } 0\end{array}$ & $\begin{array}{l}\text { VOC-1: } 0 \\
\text { VOC-2: } 10 \mathrm{~s} \\
\text { VOC-3: } 2 \mathrm{~s}\end{array}$ & $74 \mathrm{~s}$ \\
\hline N7C: $17 \mathrm{~s}$ & $\begin{array}{l}\text { GAZ-1: } 1 \mathrm{~s} \\
\text { GAZ-2: } 0\end{array}$ & $\begin{array}{l}\text { PMA-1: } 0 \\
\text { PMA-2: } 0\end{array}$ & $\begin{array}{l}\text { VOC-1: } 0 \\
\text { VOC-2: } 0 \\
\text { VOC-3: } 0\end{array}$ & $1 \mathrm{~s}$ \\
\hline
\end{tabular}


Appendix 2: Duration of joint attentional responses in each segment (after adjustment)

\begin{tabular}{|c|c|c|c|c|}
\hline & \multicolumn{4}{|c|}{ Duration of joint attentional responses } \\
\hline & GAZ (+) & PMA (+) & VOC (+) & $\begin{array}{l}\text { Total value of } \\
\text { joint attention }\end{array}$ \\
\hline \multicolumn{5}{|l|}{$\underline{\text { Session } 1}$} \\
\hline $\begin{array}{l}\text { Motifs A } \\
\text { (M1A) }\end{array}$ & $1.03 \mathrm{~s}$ & $0.62 \mathrm{~s}$ & $0.21 \mathrm{~s}$ & $1.86 \mathrm{~s}$ \\
\hline $\begin{array}{l}\text { No Motifs } \\
\text { (N1A) }\end{array}$ & 0 & 0 & 0 & $\mathbf{0}$ \\
\hline $\begin{array}{l}\text { Motifs B } \\
\text { (M1B) }\end{array}$ & $3.60 \mathrm{~s}$ & 0 & 0 & $3.60 \mathrm{~s}$ \\
\hline $\begin{array}{l}\text { No Motifs } \\
\text { (N1B) }\end{array}$ & 0 & 0 & 0 & $\mathbf{0}$ \\
\hline $\begin{array}{l}\text { Motifs C } \\
\text { (M1C) }\end{array}$ & $4.77 \mathrm{~s}$ & $0.38 \mathrm{~s}$ & $0.38 \mathrm{~s}$ & $5.54 \mathrm{~s}$ \\
\hline $\begin{array}{l}\text { No Motifs } \\
\text { (N1C) }\end{array}$ & 0 & 0 & 0 & $\mathbf{0}$ \\
\hline \multicolumn{5}{|l|}{$\underline{\text { Session } 3}$} \\
\hline $\begin{array}{l}\text { Motifs A } \\
(\mathrm{M} 3 \mathrm{~A})\end{array}$ & $0.96 \mathrm{~s}$ & $4.56 \mathrm{~s}$ & $1.20 \mathrm{~s}$ & $6.72 \mathrm{~s}$ \\
\hline $\begin{array}{l}\text { No Motifs } \\
\text { (N3A) }\end{array}$ & $1.71 \mathrm{~s}$ & 0 & $1.71 \mathrm{~s}$ & 3.43s \\
\hline $\begin{array}{l}\text { Motifs B } \\
\text { (M3B) }\end{array}$ & $0.95 \mathrm{~s}$ & $3.79 \mathrm{~s}$ & $0.63 \mathrm{~s}$ & $5.37 \mathrm{~s}$ \\
\hline $\begin{array}{l}\text { No Motifs } \\
\text { (N3B) }\end{array}$ & $0.60 \mathrm{~s}$ & 0 & $1.80 \mathrm{~s}$ & $2.40 \mathrm{~s}$ \\
\hline $\begin{array}{l}\text { Motifs C } \\
(\mathrm{M} 3 \mathrm{C})\end{array}$ & $2.50 \mathrm{~s}$ & 0 & $1.17 \mathrm{~s}$ & $3.67 s$ \\
\hline
\end{tabular}




\begin{tabular}{|c|c|c|c|c|}
\hline $\begin{array}{l}\text { No Motifs } \\
\text { (N3C) }\end{array}$ & $1.71 \mathrm{~s}$ & 0 & $1.71 \mathrm{~s}$ & $3.43 \mathrm{~s}$ \\
\hline \multicolumn{5}{|l|}{$\underline{\text { Session } 5}$} \\
\hline $\begin{array}{l}\text { Motifs A } \\
\text { (M5A) }\end{array}$ & $1.00 \mathrm{~s}$ & $7.33 \mathrm{~s}$ & 0 & $8.33 \mathrm{~s}$ \\
\hline $\begin{array}{l}\text { No Motifs } \\
\text { (N5A) }\end{array}$ & $0.43 \mathrm{~s}$ & 0 & $1.29 \mathrm{~s}$ & $1.71 \mathrm{~s}$ \\
\hline $\begin{array}{l}\text { Motifs B } \\
\text { (M5B) }\end{array}$ & $1.39 \mathrm{~s}$ & $6.54 \mathrm{~s}$ & $0.21 \mathrm{~s}$ & $8.14 s$ \\
\hline $\begin{array}{l}\text { No Motifs } \\
\text { (N5B) }\end{array}$ & $0.43 \mathrm{~s}$ & 0 & $1.29 \mathrm{~s}$ & $1.71 \mathrm{~s}$ \\
\hline $\begin{array}{l}\text { Motifs C } \\
\text { (M5C) }\end{array}$ & $3.87 \mathrm{~s}$ & $2.71 \mathrm{~s}$ & $2.71 \mathrm{~s}$ & $9.29 \mathrm{~s}$ \\
\hline $\begin{array}{l}\text { No Motifs } \\
\text { (N5C) }\end{array}$ & $0.22 \mathrm{~s}$ & 0 & $0.44 \mathrm{~s}$ & $0.67 \mathrm{~s}$ \\
\hline \multicolumn{5}{|l|}{$\underline{\text { Session } 7}$} \\
\hline $\begin{array}{l}\text { Motifs A } \\
(\mathrm{M} 7 \mathrm{~A})\end{array}$ & $3.53 \mathrm{~s}$ & $2.82 \mathrm{~s}$ & $1.41 \mathrm{~s}$ & $7.76 \mathrm{~s}$ \\
\hline $\begin{array}{l}\text { No Motifs } \\
\text { (N7A) }\end{array}$ & $0.71 \mathrm{~s}$ & 0 & 0 & $0.71 s$ \\
\hline $\begin{array}{l}\text { Motifs B } \\
\text { (M7B) }\end{array}$ & $8.64 \mathrm{~s}$ & 0 & $2.40 \mathrm{~s}$ & $11.04 \mathrm{~s}$ \\
\hline $\begin{array}{l}\text { No Motifs } \\
\text { (N7B) }\end{array}$ & 0 & 0 & 0 & $\mathbf{0}$ \\
\hline $\begin{array}{l}\text { Motifs C } \\
(\mathrm{M} 7 \mathrm{C})\end{array}$ & $9.07 \mathrm{~s}$ & 0 & $1.76 \mathrm{~s}$ & $10.83 \mathrm{~s}$ \\
\hline $\begin{array}{l}\text { No Motifs } \\
\text { (N7C) }\end{array}$ & $0.71 \mathrm{~s}$ & 0 & 0 & $0.71 \mathrm{~s}$ \\
\hline
\end{tabular}




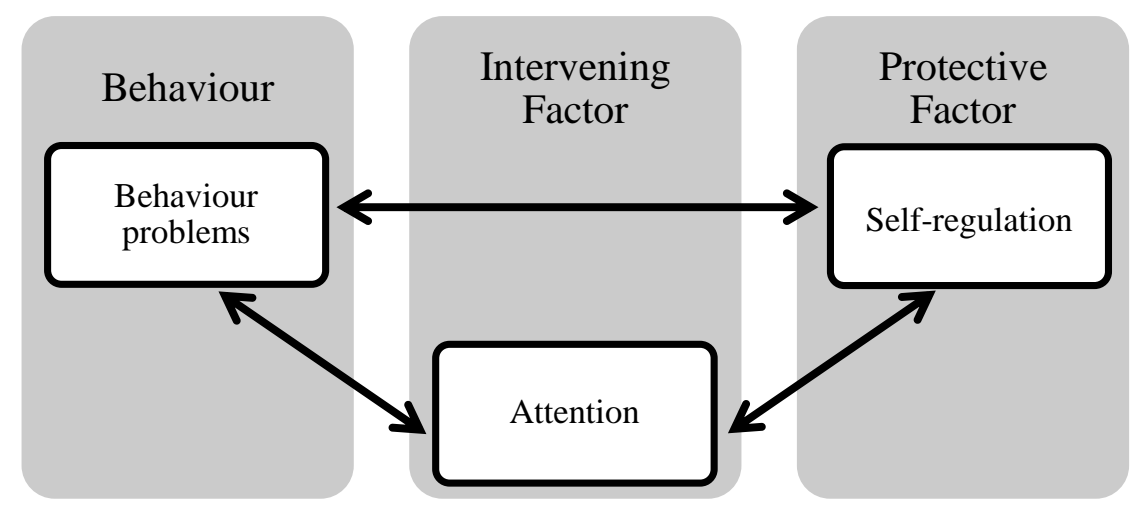

Figure 1. Relationships between EBP, self-regulation and attention.

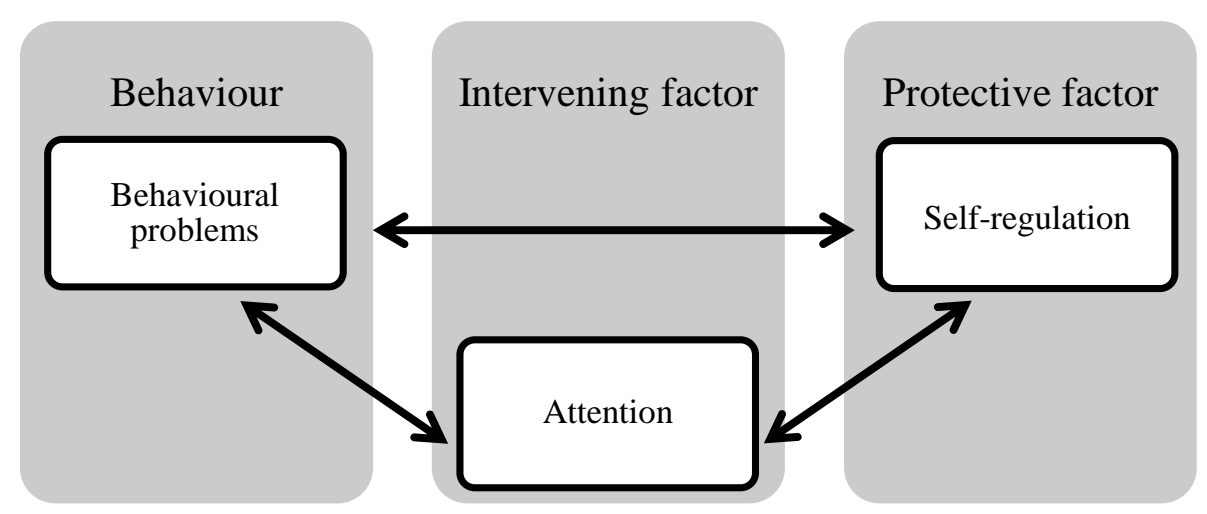

Figure 2. Theoretical framework of the presenting problems. 


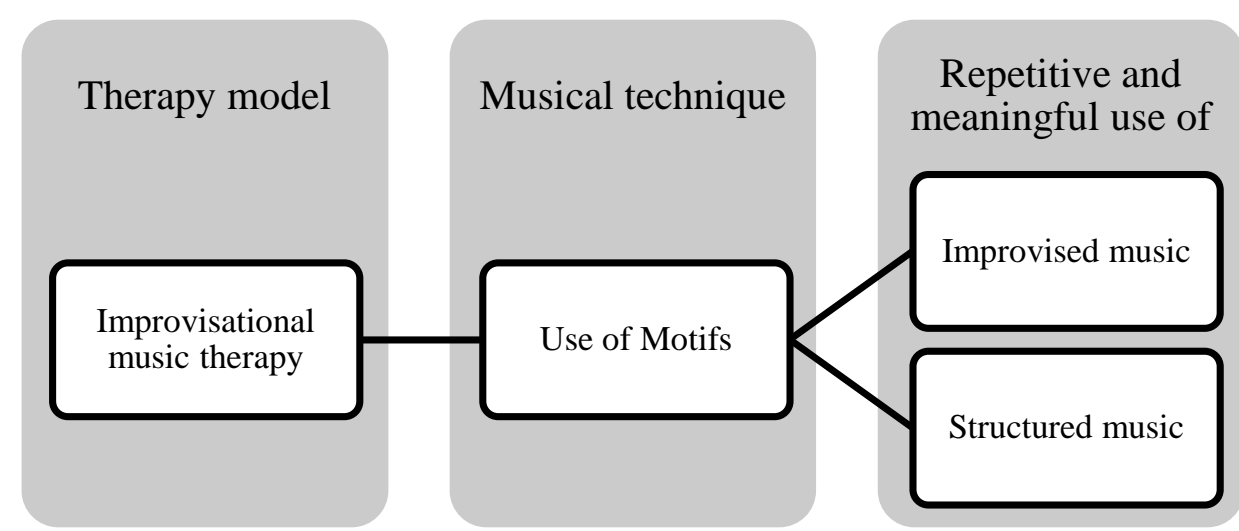

Figure 3. Theoretical framework of the interventions. 


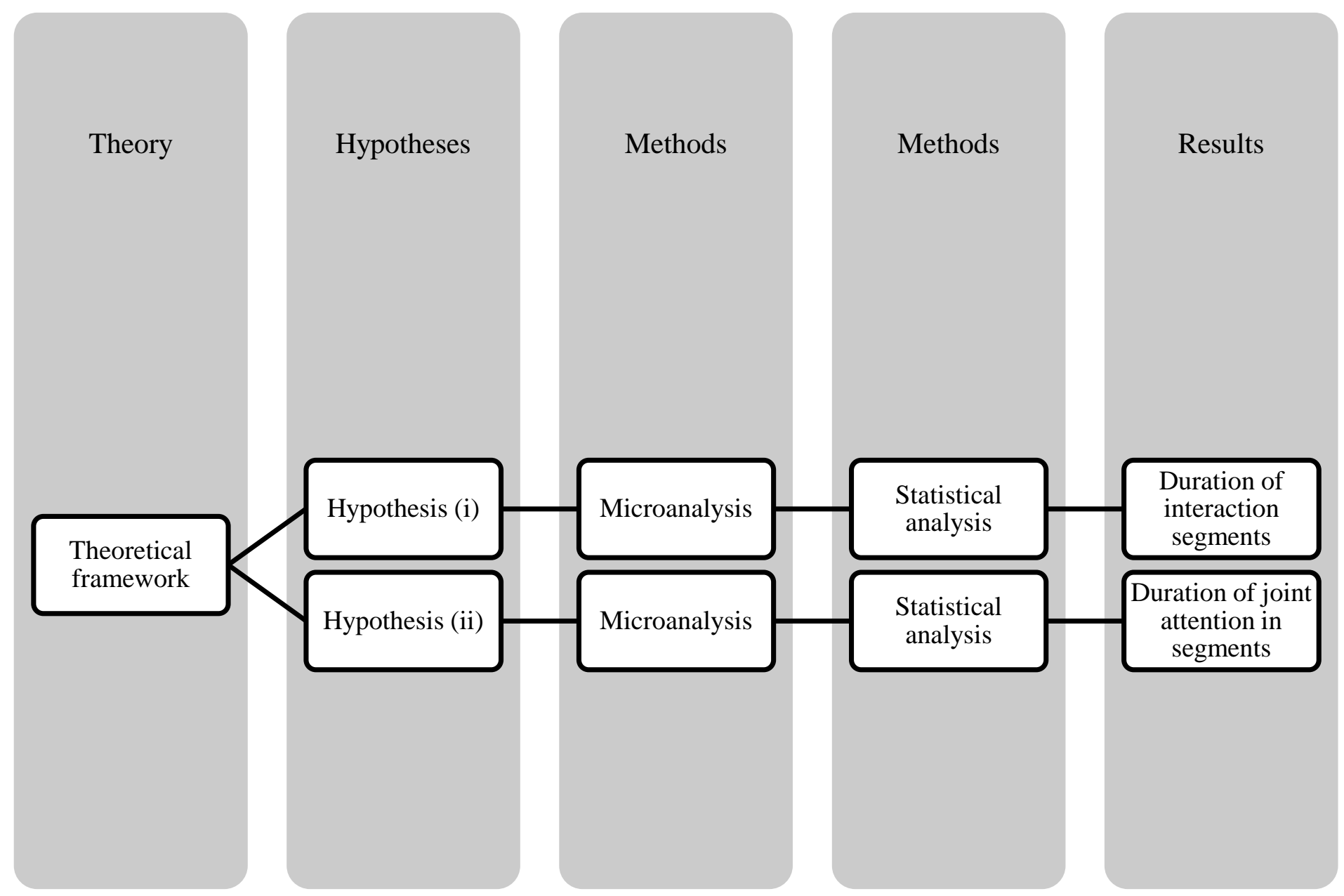

Figure 4. Overall framework of the project's design. 
Table 1. Coding system for interaction segments.

\begin{tabular}{|c|c|c|}
\hline Presence/absence of Motifs & $\underline{\text { Session no. }}$ & $\underline{\text { Type of Motifs }}$ \\
\hline M & 1 & A \\
\hline N & 3 & B \\
\hline & 5 & C \\
\hline & 7 & \\
\hline
\end{tabular}


Table 2. Communication categories of the child.

\begin{tabular}{|l|l|l|}
\hline Gaze (GAZ) & Play/musical activity (PMA) & Vocalisations (VOC) \\
\hline $\begin{array}{l}\text { GAZ-1 (+) } \\
\text { Gazes at } \\
\text { therapist/therapist's face }\end{array}$ & $\begin{array}{l}\text { PMA-1 (+) } \\
\text { Playing an instrument } \\
\text { (responding to therapist's } \\
\text { playing) }\end{array}$ & $\begin{array}{l}\text { VOC-1 (+) } \\
\text { Singing }\end{array}$ \\
\hline $\begin{array}{l}\text { GAZ-2 (+) } \\
\text { Gazes at therapist's } \\
\text { instrument }\end{array}$ & $\begin{array}{l}\text { PMA-2 (+) } \\
\text { Moving } \\
\text { rhythmically/purposefully } \\
\text { (responding to therapist's } \\
\text { playing) }\end{array}$ & Vaughing \\
\hline $\begin{array}{l}\text { GAZ-3 (-) } \\
\text { Gazes at own instrument }\end{array}$ & $\begin{array}{l}\text { PMA-3 (-) } \\
\text { Playing an instrument } \\
\text { (without responding to } \\
\text { therapist's playing) }\end{array}$ & Talking \\
\hline $\begin{array}{l}\text { GAZ-4 (-) } \\
\text { Gazes at an random } \\
\text { object }\end{array}$ & $\begin{array}{l}\text { PMA-4 (-) } \\
\text { Moving randomly (without } \\
\text { responding to therapist's } \\
\text { playing) }\end{array}$ & Moaning \\
\hline $\begin{array}{l}\text { GAZ-5 (-) } \\
\text { Gaze around the room }\end{array}$ & $\begin{array}{l}\text { PMA-5 (-) } \\
\text { Touching an instrument }\end{array}$ & VOC-5 (-) \\
Crying
\end{tabular}




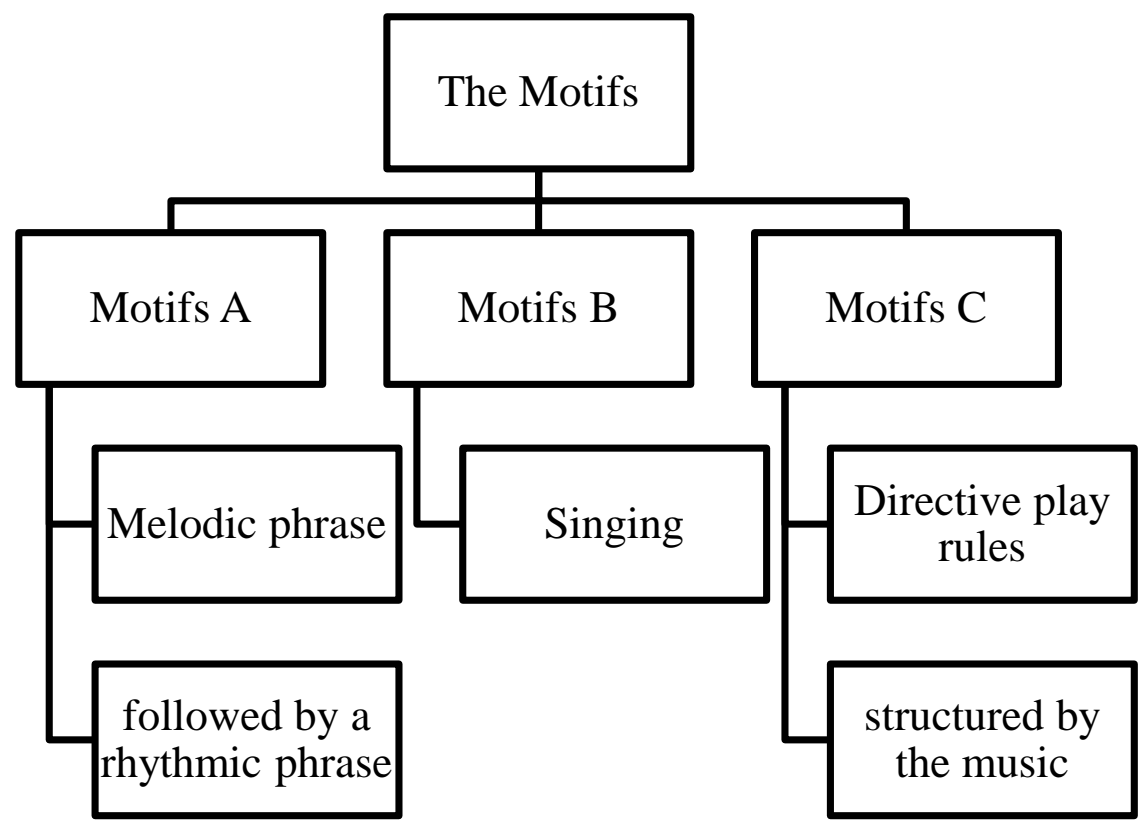

Figure 5. Outline of Motifs found. 


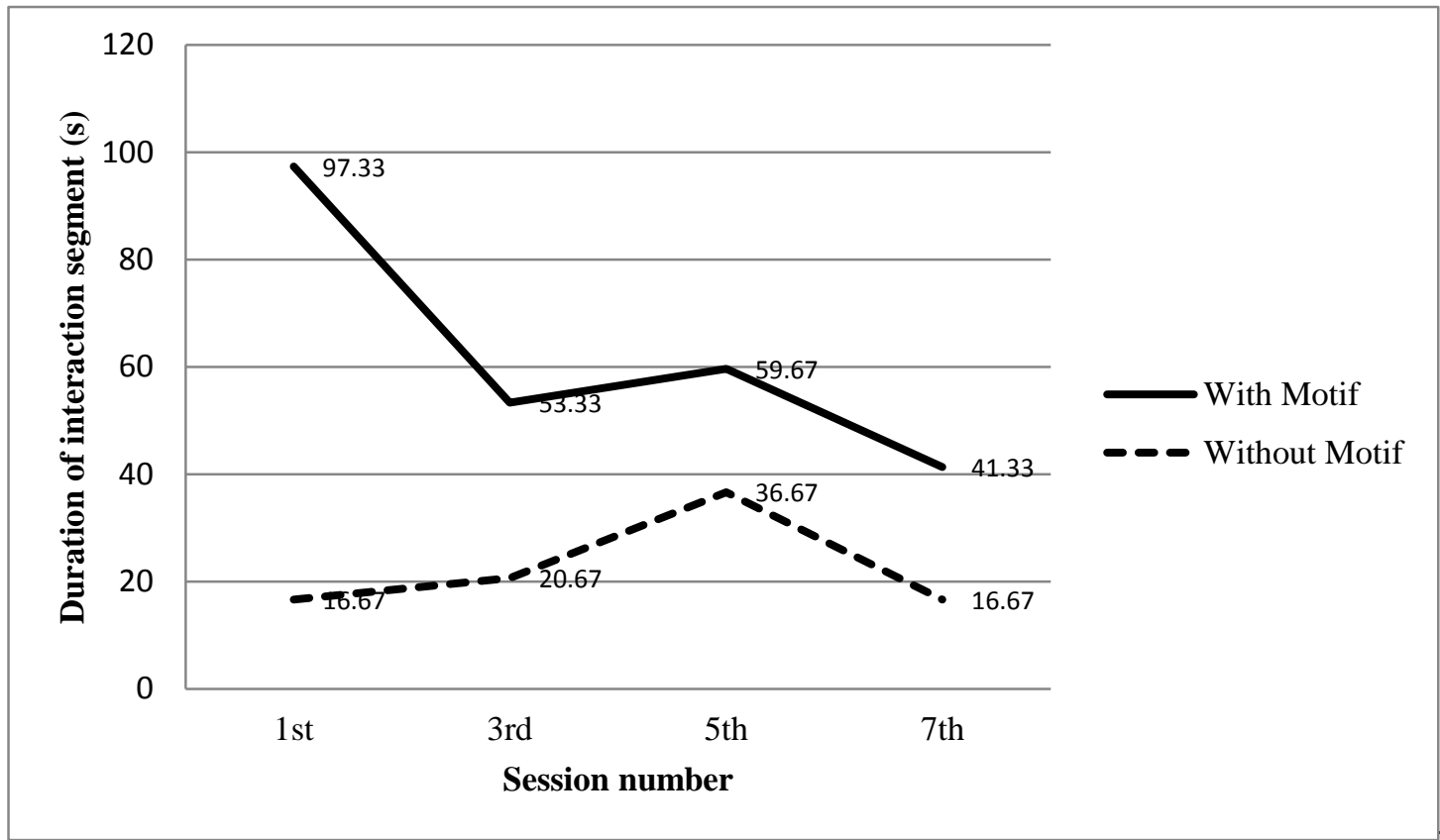

Figure 6. Changes in duration of Motifs/no-Motifs segments across sessions. 


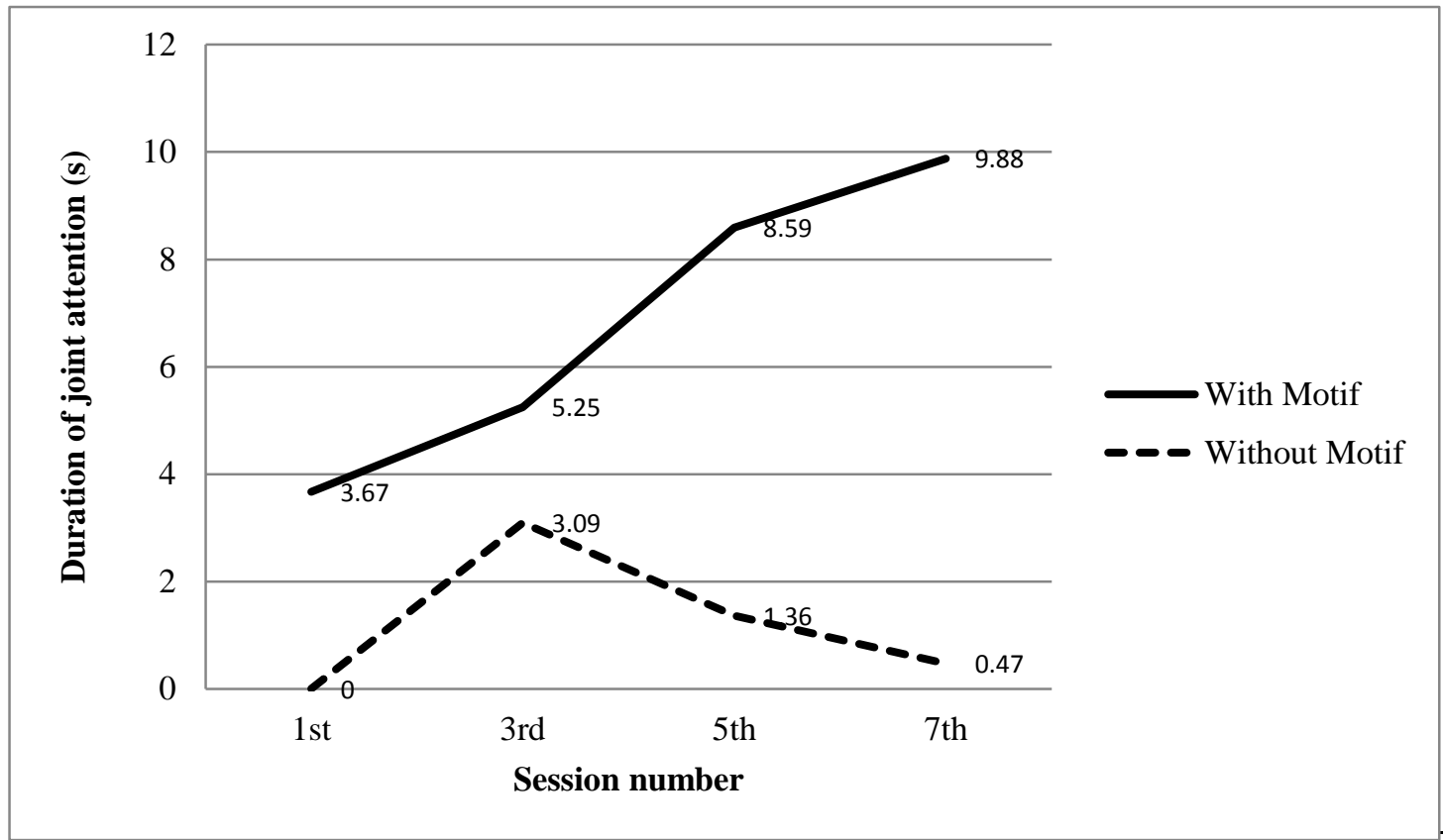

Figure 7. Changes in duration of joint attention in segments across sessions. 


\section{Ethical approval}

Ethical approval for this project was given by Anglia Ruskin University's Departmental Research Ethics Panel (DREP).

\section{Funding}

This article is an abridged and edited version of my MA Music Therapy final-year thesis at Anglia Ruskin University, Cambridge. The author(s) received no financial support for the research, authorship, and/or publication of this article.

\section{Acknowledgements}

I would like to thank my supervisor, Professor Jörg Fachner for his valuable input and comments on this academic work. 